\title{
NOTATIONAL ANALYSIS OF BEACH HANDBALL
}

original paper

(c) Wroclaw University of Health and Sport Sciences

DOI: https://doi.org/10.5114/hm.2021.101757

\author{
ALICE IANNACCONE ${ }^{1}$, ANDREA FUSCO ${ }^{1}$, DANIELE CONTE ${ }^{2}$, CRISTINA CORTIS ${ }^{1}$ \\ ${ }^{1}$ Department of Human Sciences, Society and Health, University of Cassino and Lazio Meridionale, Cassino, Italy \\ ${ }^{2}$ Institute of Sport Science and Innovations, Lithuanian Sports University, Kaunas, Lithuania
}

\section{ABSTRACT}

Purpose. One factor affecting successful performance in beach handball is the efficiency of shootings. As only few studies evaluated gender-related differences in shooting performance, the aim of this study was to analyse variations of shooting efficiency between males $(\mathrm{M})$ and females $(\mathrm{F})$ during beach handball matches.

Methods. Nine matches were analysed. Overall, there were 559 (M: 353; F: 206) shots, of which $54.7 \pm 9.4 \%$ were successful and $19.9 \pm 7.1 \%$ were goalkeepers' saves. Type of shot, shooting area, and goal area were recorded. Percentages of differences between genders were also computed. Players' efficiency was calculated as (frequency of goals* 100 )/frequency of shots. Goalkeepers' efficiency was calculated as (frequency of goalkeepers' saves*100)/frequency of shots. Gender differences were ascertained by Pearson's chi-squared test for independence with Bonferroni corrections. Statistical significance of the results was accepted at $p<0.05$.

Results. No statistically significant gender differences were found for any parameter. Goalkeepers were most efficient (M: $23.0 \pm 6.1 \%$; F: $25.9 \pm 18.0 \%$ ) when receiving inflight shots. The most frequent shooting area was the front (M: 328 shots; F: 194 shots) and most shots reached lower corners of the goal (M: 139 shots; F: 77 shots).

Conclusions. No differences between genders were found during semifinal and final phases of the tournament. Notational analysis proved to be a valuable tool for better coaching through the interpretation of shots in beach handball and it may be useful to examine all the aspects related to shooting, such as the shooting area and the goal area.

Key words: performance, team sports, match analysis, technical indicators, shooting, competition

\section{Introduction}

Beach handball is a team sport played on a $27 \times$ $12 \mathrm{~m}$ sand court by 2 teams, each composed of 1 goalkeeper (GK) and 3 field players. With the rule of free substitutions, during the offensive phases, the GK is allowed to exit the goal area and be changed by a field player, a specialist, creating a situation of numerical superiority [1]. A match includes two 10-minute sets with a golden goal in the case of a tied set and a series of 5 shoot-outs in the event of a tied match. Beach handball matches have a peculiar structure defined as cyclic eight, characterized by a concurrent transition between the offensive and defensive phases [2]. The numerical superiority created by a specialist temporarily substituting the GK generates more opportu- nities to create spaces and more ways to score 2 points where the specialist plays a crucial role in the creation of offensive situations [3]. Successful offensive situations are expressed as shootings with their relative effectiveness [4], representing one of the main factors that contribute to the success of team sport [5].

Reflecting the studies on indoor handball [6-9], research on beach handball has focused on physiological and kinematic aspects [10-14], individual and team performance [3, 15], and shooting analysis $[4,16,17]$. Several moderate-to-high intensity activities distributed intermittently throughout the match characterize beach handball, with males performing more moderate and high intensity accelerations than females [10] and kinematics variables (i.e., total distance, body load, impacts, speed average) decreasing in the second set

Correspondence address: Cristina Cortis, Department of Human Sciences, Society and Health, University of Cassino and Lazio Meridionale, Via S. Angelo - Località Folcara, 03043 Cassino (FR), Italy, e-mail: c.cortis@unicas.it

Received: March 31, 2020

Accepted for publication: November 7, 2020

Citation: Iannaccone A, Fusco A, Conte D, Cortis C. Notational analysis of beach handball. Hum Mov. 2022;23(1):69-79; doi: https://doi.org/10.5114/hm.2021.101757. 
A. Iannaccone, A. Fusco, D. Conte, C. Cortis, Notational analysis of beach handball

for both males and females [13]. In a recent study [14], differences in the conditional assessment of the specific playing positions (specialist, wing, fixed wing, pivot, defender) of elite beach handball players have been investigated for male and female players. Significant gender-related differences emerged in the conditional data of competition, with variability depending on the playing position, both in men and women.

Compared with indoor handball, beach handball players cover a lower distance (males: $3627 \pm 568 \mathrm{~m}$, females: $4002 \pm 551 \mathrm{~m}$ in indoor handball [18]; males: $1235 \pm 192 \mathrm{~m}$, females: $1118 \pm 222 \mathrm{~m}$ in beach handball [10]) and there is a lower number of accelerations owing to the sandy surface, placing higher physiological demands on players [10]. To the best of our knowledge, only 1 study [3] has focused solely on the shooting actions during beach handball matches, showing that match analysis may provide specific insights useful for training plans and drills for a better preparation [19]. For instance, in other team sports, it has been reported [20] that the frequency of occurrence of passes, shots, goals, shots originating from different zones of the court, and the type of shots performed are the performance indicators better discriminating among competition levels. The importance of match analysis in team sports has also been highlighted by Hatzimanouil [21], who analysed the effectiveness of shots by shooting areas and by playing positions among highlevel handball players by means of a video analysis. The majority $(56.9 \%)$ of throws were successful, with a higher frequency of shots originating from the central attack area from a medium distance and ending to the left lower side of the goal. Nevertheless, the efficacy of shots was heterogeneous among the different attacking areas and player positions.

Findings from a systematic review on match analysis in handball [22] show that studies examined players' and teams' performance from 2 different perspectives. The most popular perspective is considering the classical static complexity approach based on recording players' and teams' actions (usually in terms of descriptive frequencies of events) to obtain a final dataset describing what happened at the end of the match, without considering how it happened. The other perspective takes into account the new dynamic complexity approach, wherein action recording considers the chronological and sequential order in which the actions occur. Looking at the utility of performance analysis, a study [23] examined the involvement with match, notational, and technique analysis of 46 elite professional and semiprofessional coaches of different team sports (i.e., rugby league, hockey, football, basket- ball, rugby union). Findings revealed that the information provided by performance analysis gave coaches useful feedback about their short-term (93\%), medium-term (80\%), and long-term (70\%) planning. In addition, $86 \%$ of the interviewed coaches confirmed that performance analysis was 'essential' or 'very useful' for applying specific changes in their training and game strategies. Therefore, it is crucial to identify the performance indicators of the sport to give appropriate feedback to coaches and practitioners. To be useful, performance indicators should relate to successful performance or outcome [24].

In beach handball, performance depends on the combination of high intensity physical patterns at the player and team level. The player performance depends on specific movements involving speed and power, rapid accelerations and decelerations, and changes in directions [10, 11, 24], whereas the overall team performance depends on technical and tactical team performance indicators, such as passing, catching, throwing, checking, and blocking during offensive and defensive situations [7, 25]. Thus, successful performance results from the combination of performance indicators, such as passes, shots, and field positions, representing a selection or combination of variables aimed to define some or all aspects of performance [24]. For beach handball, better differentiators between winning and losing teams are the variables involving a combination of other ones in the calculation of their score, such as the GK's received and blocked shots, or shots attempts made by shooters and blocks, reflecting the importance of the GK in a team's victory, as well as the value of goals, blocks, and technical fouls [26]. In fact, the evaluation of goals is based on the shooting technique: attractive goals or goals made by specialist players are awarded 2 points, whereas non-attractive goals score 1 point [3].

Jimenez-Olmedo et al. [15] showed that specific anthropometric characteristics (i.e., elbow perimeters and dimension of hand polygons) were positively correlated with throwing performance in beach handball players, in particular among the specialists. However, because overarm throw is a multi-joint movement with many potential degrees of freedom, basic anthropometric parameters proved to be more important than hand dimensions [15]. In addition to an individual's throwing capacity, cooperation among players is crucial for successful shooting performance [3]. Regarding the position of the shots, the right side has been reported the most efficient shooting position for males [4], although the highest frequency refers to shooting from the centre $[4,16]$; for females, shooting from the centre 
shows the highest frequency and efficiency $[4,16]$. Gender differences have also been revealed in terms of behaviours that occur during the positional attack phases, with males ending the offensive phases on the outer edges of the playing court [17] and females on the left side [27]. Furthermore, different behaviours have been described when the attack ends with an inflight shot, with males tending to use this type of shot when they are winning and females when they are tied or losing [17].

It is evident that studies on beach handball have focused on different points of view and there is still ongoing research contributing to its developing process [28]. In particular, few studies have been conducted with the aim to analyse gender differences in shooting performance. Therefore, to contribute to the further development of the sport, the aim of this study was to analyse the variations of shooting efficiency between male and female beach handball players.

\section{Material and methods}

Experimental approach to the problem

According to the rules of the game of beach handball [1], players may use different type of shots to score a goal (Table 1).

Since the success of a shot is the result of a combination of different performance indicators [5], the analysis focused on performance indicators as described in Table 2.

By adapting the models proposed for notational analysis [5], the playing field was divided into 3 horizontal areas (front, centre, back) measuring $6 \times 5 \mathrm{~m}$ each and 2 vertical areas (right and left) measuring 6 $\times 15 \mathrm{~m}$ each, and the goal was divided into 4 corners (upper left, lower left, upper right, lower right) measuring $1.5 \times 2 \mathrm{~m}$ each, as shown in Figure 1 .

Table 1. Classification of the types of shots used in beach handball according to the rules of the game proposed by the International Handball Federation [1]

\begin{tabular}{llc}
\hline Type of shot & \multicolumn{1}{c}{ Description } & Points \\
\hline Inflight & Performed while flying through the air & 2 \\
Spin shot & Taken with full turn of the body in the air & 2 \\
Specialist & Performed by the specialist player & 2 \\
Directive goal & Performed by the goalkeeper from the goal area & 2 \\
6-m shot & Penalty throw performed from the 6-m line & 2 \\
One pointer & Non-attractive shot & 1 \\
\hline
\end{tabular}

Table 2. Description of the performance indicators of beach handball

\begin{tabular}{ll}
\hline Performance indicators & \multicolumn{1}{c}{ Description } \\
\hline Shooting area & Area of the playing field from which the shot is performed \\
Goal corner & Corner of the goal to which the ball is thrown \\
Successful shot & Shot ended with a scored goal \\
Goalkeeper's save & Goal not scored because of a block from the goalkeeper \\
\hline
\end{tabular}

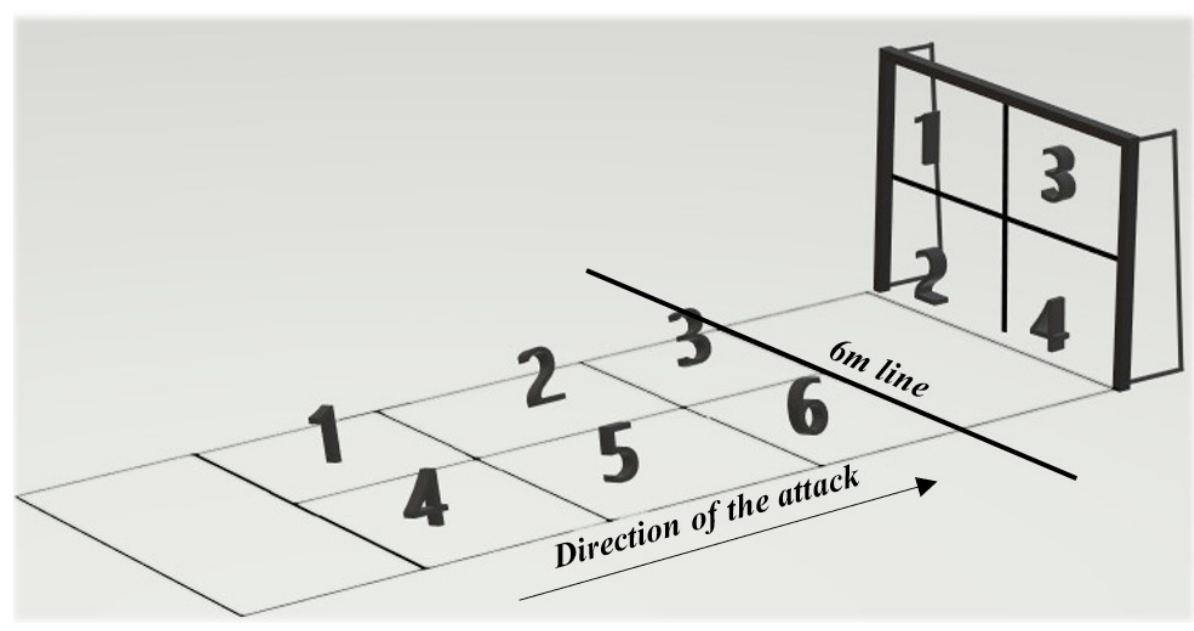

Shooting areas:

3,6 - front

2, 5 - centre

$1,4-$ back

$1,2,3-$ left

4, 5, 6-right

Goal areas:

1,3- upper corners

2, 4 - lower corners

1,2 - left side

3,4 - right side

Figure 1. Representation of the shooting and goal areas from the players' point of view 
A. Iannaccone, A. Fusco, D. Conte, C. Cortis, Notational analysis of beach handball

\section{Sample}

The Calise Cup tournament is a beach handball competition for clubs held every year in Italy. The tournament lasts 3 days (temperature: $29.6 \pm 1.3^{\circ} \mathrm{C}$; humidity: $58.6 \pm 11.8 \%$ ): the first 2 days are dedicated to eliminatory phases (played on 2 different courts at the same time), while during the last day, semifinals and finals occur (1 match at a time in the main arena). Each team plays at least 5 matches all along the tournament. Before starting the video-recording for the study, the framing for all the 3 playing courts was checked and they were all different. Only the court used for the semifinals and finals allowed a full and satisfying view of the court. Therefore, to ensure the reliability of video-recording, only matches played on the main arena during the semifinal and final phases of the tournament were considered for the present study (10 male seniors, 10 female seniors, 8 male U18, and 4 male U12). However, after preliminary analysis, differences in technical-tactical actions were observed between U12 players and the rest of the sample. Therefore, U12 matches were excluded from the final sample; the same referred to matches during which technical issues happened while recording, thus leaving a final number of 9 analysed matches, involving 4 male senior (Chemo profili Zagreb, Albena Beach Bulgaria, Beach Stars BHC, Zagreb Beach Hrvatska), 4 male U18 (Göteborg B.H. Club, Zagreb Beach Hrvatska, Pallamano Grosseto, BHC Cus Cassino), and 4 female (Beach Queens, Beach Princesses, Team Enigma Web Design The Danish Beach Handball Dream, Cannabis Energy Drink Beach Handball Club) teams.

As performance analysis could provide a valuable estimate of technical and tactical aspects of team sports [5], it was hypothesized that examining the efficiency of players during the final phases of the tournament (i.e., semifinals and finals) would increase the relevance and applicability of the results for coaches and practitioners.

\section{Procedures}

The matches were recorded by 2 experienced researchers (C.C. and A.F.) by means of a video camera (Sony Camcorder HR-CX290/B, Sony, Minato, Tokyo, Japan) fixed at one side of the field, allowing a full view of the playing area. After each match, the recorded video was downloaded and used for further analysis. For the video analysis, carried out by 2 experienced observers (A.I. and D.C.), a keyboard created ad hoc with the Dartfish TeamPro 5.0 software (Dartfish, Fribourg, Switzerland) was used.

\section{Preliminary analysis}

Notational analysis involves an objective way of recording performance, so that critical events in that performance can be quantified in a consistent and reliable manner, allowing to obtain useful feedback, crucial in the performance improvement process [5]. In this context, it is necessary that the feedback is accurate and precise. Therefore, before proceeding with the statistical analysis, accuracy and reliability of the data gathered through the video analysis were assessed. In line with previous notational analyses $[18,19]$, to provide a reliable analysis, the intra- and inter-observer reliabilities were established. Before the study, the observers scored twice 3 randomly selected matches, with 7-day breaks between the observations. The intra- and inter-observer reliabilities were ascertained by using the weighted kappa statistic [29] for each observed variable (Table 2) and interpreted in accordance with the guidelines proposed by Landis and Koch [30]. Table 3 shows the results for the intra-observer reliability of the 2 observers, as well as the inter-observer reliability.

For all the variables, values were classified strong or moderate, except for the intra-observer reliability of observer 1 for one pointer shot (fair agreement). Since the kappa statistics is based on the proportion of frequencies of events and few one pointer shots were recorded, the percentages of agreement were considered as acceptable.

\section{Statistical analysis}

Absolute and relative frequencies were calculated for each variable. In particular, absolute frequency is defined as the total number of observed events, whereas the relative frequency represents the number of observed events relative to the absolute frequency expressed as percentage. Means and standard deviations of the relative frequencies per match were calculated for each variable and they were used in a statistical sense. Gender differences in frequencies of shots, GKs' saves, and goals in relation to the type of shot, the shooting area, and the goal area were ascertained by Pearson's chi-squared test for independence. Where significant results were found, Bonferroni corrections for multiple post-hoc comparisons were applied. Since a different number of matches were recorded for males and females, to allow comparison between gender, the percentages of differences between means of male and female players were computed and efficiencies of players and GKs were calculated in accordance with the equations proposed by O'Donoghue and Holmes [31]: 
Table 3. Intra- and inter-observer reliabilities for the variables observed for the analysis

\begin{tabular}{|c|c|c|c|c|c|c|c|c|c|}
\hline \multirow{2}{*}{ Variable } & \multicolumn{3}{|c|}{ Agreement (\%) } & \multicolumn{3}{|c|}{ Expected agreement (\%) } & \multicolumn{3}{|c|}{ Карра } \\
\hline & O1 & $\mathrm{O} 2$ & O1 vs. O2 & O1 & $\mathrm{O} 2$ & O1 vs. O2 & O1 & $\mathrm{O} 2$ & O1 vs. O2 \\
\hline \multicolumn{10}{|l|}{ Type of shot } \\
\hline Spin shot & 96.0 & 96.8 & 96.3 & 65.2 & 63.3 & 63.5 & 0.88 & 0.91 & 0.90 \\
\hline Specialist & 96.1 & 97.4 & 98.0 & 72.0 & 76.5 & 77.2 & 0.86 & 0.88 & 0.91 \\
\hline Inflight & 95.4 & 98.5 & 97.2 & 71.4 & 76.5 & 76.3 & 0.84 & 0.94 & 0.88 \\
\hline One pointer & 98.4 & 97.6 & 97.1 & 97.6 & 94.8 & 95.3 & 0.32 & 0.54 & 0.46 \\
\hline Directive goal & 98.9 & 99.7 & 98.3 & 93.4 & 71.7 & 95.0 & 0.83 & 0.99 & 0.67 \\
\hline $6-m$ shot & 99.3 & 99.7 & 99.7 & 93.7 & 75.2 & 90.6 & 0.88 & 0.99 & 0.97 \\
\hline \multicolumn{10}{|l|}{ Shooting area } \\
\hline Front & 99.1 & 99.1 & 98.7 & 89.2 & 94.1 & 90.7 & 0.91 & 0.85 & 0.86 \\
\hline Centre & 98.4 & 99.3 & 97.1 & 96.4 & 98.4 & 96.2 & 0.56 & 0.57 & 0.54 \\
\hline Back & 96.9 & 98.8 & 98 & 91.0 & 95.2 & 93.6 & 0.65 & 0.76 & 0.69 \\
\hline Right/left side & 95.7 & 91.7 & 88.6 & 61.9 & 58.3 & 58.5 & 0.89 & 0.80 & 0.73 \\
\hline Goal area & & & & & & & & & \\
\hline Upper/lower corner & 88.7 & 87.0 & 89.8 & 68.0 & 68.4 & 69.7 & 0.64 & 0.59 & 0.66 \\
\hline Right/left side & 92.7 & 85.6 & 83.0 & 66.5 & 61.4 & 62.8 & 0.78 & 0.63 & 0.54 \\
\hline \multicolumn{10}{|l|}{ Shot's outcome } \\
\hline Successful/unsuccessful shot & 98.6 & 94.9 & 95.1 & 64.4 & 75.5 & 56.3 & 0.96 & 0.80 & 0.89 \\
\hline
\end{tabular}

O1 - observer 1 , O2 - observer 2

\section{Players efficiency $=($ frequency of goals*100) / frequency of shots}

GKs' efficiency $=$ (frequency of GKs' saves*100) /

$$
\text { frequency of shots }
$$

Statistical analysis was performed with the Stata statistical software, version 15.1 (StataCorp, College Station, USA) and the statistical significance of the results was accepted at $p<0.05$.

\section{Ethical approval}

The research related to human use has complied with all the relevant national regulations and institutional policies, has followed the tenets of the Declaration of Helsinki, and has been approved by the Institutional Review Board of the Department of Human Sciences, Society and Health of the University of Cassino and Lazio Meridionale (approval No.: 3538.2019.02.19; date: February 19, 2019).

\section{Informed consent}

The video-recording for this study took place in a public arena and no intervention or direct interaction was required. Thus, according to the rules of competitions and the guidelines and basic ethical principles described in the Belmont Report, supporting the accessibility of images of public behaviour for the research reason on human subjects, there was no need of informed consent from the participants to enable the use of the analysed video-recordings, as these are in the public domain.

\section{Results}

In the present study, 559 shots (males: 353; females: 206) on goal made throughout 9 matches ( 2 semifinals female senior, 2 semifinals male senior, 2 final male U18, 1 final female senior, 2 final male senior) were analysed.

Among the total sample, $54.7 \pm 9.4 \%$ (males: $55.5 \pm$ 11.4\%; females: $53.3 \pm 4.3 \%$ ) of the shots were successful and $19.9 \pm 7.1 \%$ (males: $19.5 \pm 11.4 \%$; females: $20.8 \pm 8.9 \%$ ) were GKs' saves. No significant gender differences emerged for the different types of shots (Table 4).

No significant gender differences emerged for the different shooting areas (Table 5).

No significant gender differences emerged for the different goal areas (Table 6).

\section{Discussion}

The aim of this study was to analyse the variations of shooting efficiency between genders in beach handball. The findings showed that (i) no statistically significant differences between male and female players were found; (ii) GKs were more efficient when receiving inflight shots than the other types of shot; (iii) shots 
A. Iannaccone, A. Fusco, D. Conte, C. Cortis, Notational analysis of beach handball

Table 4. Absolute $(n)$ and relative (means \pm standard deviations) values, and percentages of differences between genders for frequencies of shots, GKs' saves, and goals with GKs and players efficiencies observed in relation to the type of shot in males and females

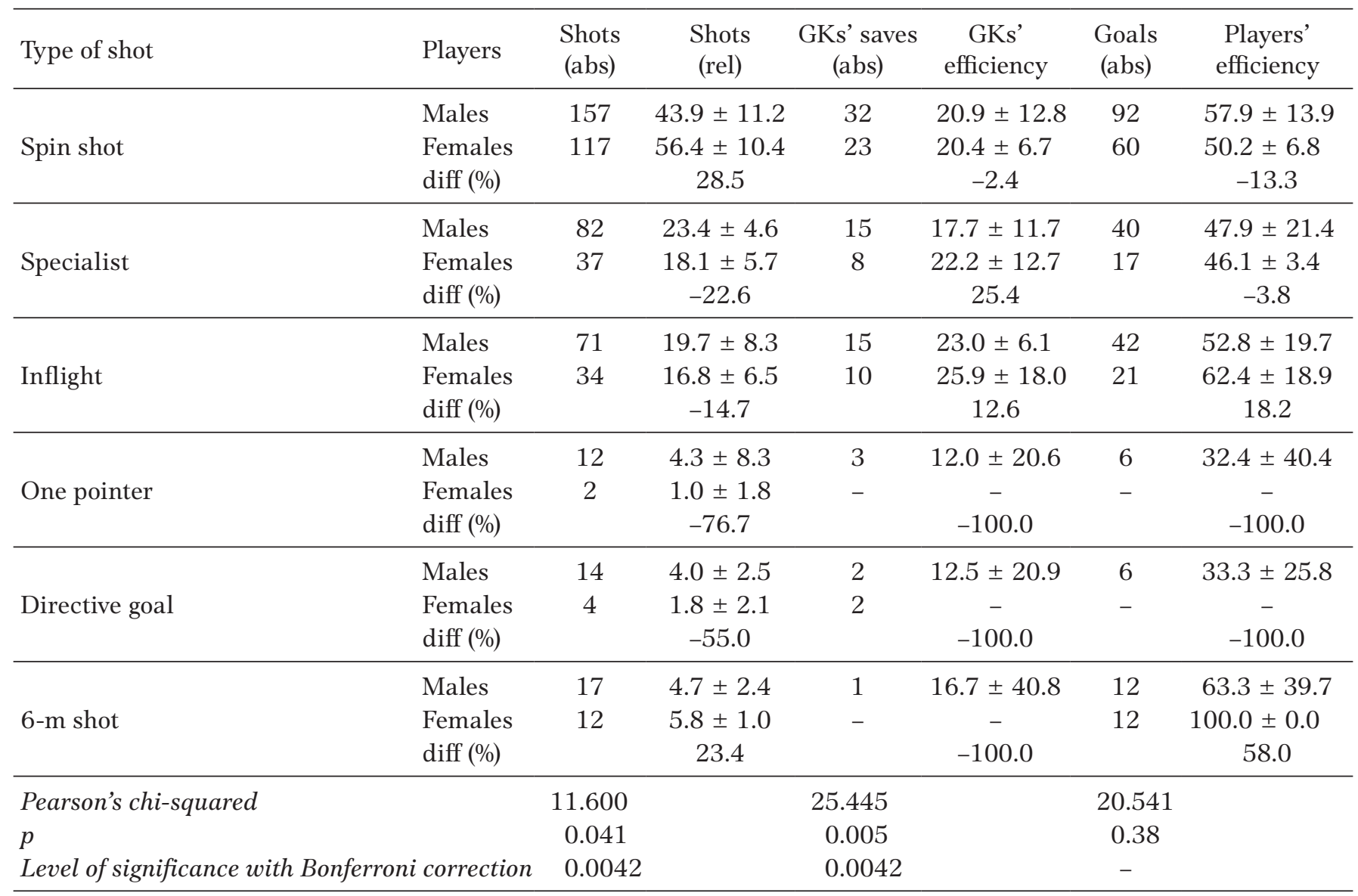

abs - absolute frequency, rel - relative frequency, GKs - goalkeepers, diff (\%) - percentage of differences

originated most frequently from the front shooting area; (iv) the majority of shots reached the lower corners of the goal.

In line with the shot frequency observed in female tournaments [32], the most frequent shot observed in the present study was the spin shot, while the least frequent was the one pointer shot. In fact, it has been reported [32] that there is a decrease over the years in the frequency of one pointer shots, suggesting a change in the attacking models adopted by the teams.

In the present study, female players showed highest efficiency values when using inflight shots over the other types of shot, not considering the 6-m shot, which will be discussed separately. GKs also presented highest efficiency values when blocking inflight shots. For male players, highest values of efficiency were found for the spin shots. Male GKs showed higher efficiency values when blocking inflight shots than the other types of shot. When comparing the percentage of differences in relative frequencies for males and females, the results, even though not statistically significant, indicate that females used more spin shots and 6-m shots than males. However, female GKs were characterized by higher values of efficiency than males when defending shots performed by the specialist or inflight shots than with the other types of shot. Moreover, female players were more efficient than males only when shooting with inflight shots, excluding 6-m shots.

These results observed for female players differ from what was previously reported [33], where field players were more efficient using spin shots, probably owing to the defensive system adopted. In fact, the defensive systems may influence the style of play of offensive teams. In particular, if the defensive team focuses on the specialist player of the opponent, leaving the outer zones of the playing field unprotected, the offensive team will probably try to shoot from those zones using spin shots [33]. Therefore, it can be assumed that the defensive systems adopted in the observed matches did not allow players to obtain higher efficiency values and resulted in higher efficiency when shooting with inflight shots as compared with the other types of shot. 
Table 5. Absolute $(n)$ and relative (means \pm standard deviations) values, and percentages of differences between genders for frequencies of shots, GKs' saves, and goals with GKs and players efficiencies observed in relation to the shooting area in males and females

\begin{tabular}{|c|c|c|c|c|c|c|c|}
\hline Shooting area & Players & $\begin{array}{l}\text { Shots } \\
(\mathrm{abs})\end{array}$ & $\begin{array}{l}\text { Shots } \\
\text { (rel) }\end{array}$ & $\begin{array}{c}\text { GKs' saves } \\
\text { (abs) }\end{array}$ & $\begin{array}{l}\text { GKs' } \\
\text { efficiency }\end{array}$ & $\begin{array}{c}\text { Goals } \\
\text { (abs) }\end{array}$ & $\begin{array}{l}\text { Players' } \\
\text { efficiency }\end{array}$ \\
\hline Front all (including 6-m shots) & $\begin{array}{l}\text { Males } \\
\text { Females } \\
\text { diff }(\%)\end{array}$ & $\begin{array}{l}328 \\
194\end{array}$ & $\begin{array}{c}92.0 \pm 6.1 \\
93.7 \pm 1.8 \\
1.8 \\
\end{array}$ & $\begin{array}{l}66 \\
43\end{array}$ & $\begin{array}{c}21.6 \pm 9.3 \\
20.6 \pm 9.1 \\
-4.6\end{array}$ & $\begin{array}{l}185 \\
108\end{array}$ & $\begin{array}{c}54.1 \pm 13.4 \\
55.9 \pm 4.8 \\
3.3\end{array}$ \\
\hline Front right & $\begin{array}{l}\text { Males } \\
\text { Females } \\
\text { diff }(\%)\end{array}$ & $\begin{array}{c}156 \\
95\end{array}$ & $\begin{array}{c}44.1 \pm 3.2 \\
46.1 \pm 0.9 \\
4.5\end{array}$ & $\begin{array}{l}35 \\
24\end{array}$ & $\begin{array}{c}22.9 \pm 10.0 \\
23.3 \pm 10.1 \\
1.7\end{array}$ & $\begin{array}{l}82 \\
53\end{array}$ & $\begin{array}{c}51.3 \pm 18.6 \\
55.8 \pm 5.0 \\
8.8\end{array}$ \\
\hline Front left & $\begin{array}{l}\text { Males } \\
\text { Females } \\
\text { diff }(\%)\end{array}$ & $\begin{array}{c}154 \\
86\end{array}$ & $\begin{array}{c}43.3 \pm 5.9 \\
41.9 \pm 2.4 \\
-3.2 \\
\end{array}$ & $\begin{array}{l}30 \\
18\end{array}$ & $\begin{array}{c}20.6 \pm 12.1 \\
20.8 \pm 12.3 \\
1.0\end{array}$ & $\begin{array}{l}90 \\
43\end{array}$ & $\begin{array}{c}57.1 \pm 14.9 \\
50.0 \pm 5.2 \\
-12.4\end{array}$ \\
\hline Centre all & $\begin{array}{l}\text { Males } \\
\text { Females } \\
\text { diff }(\%)\end{array}$ & $\begin{array}{l}6 \\
7\end{array}$ & $\begin{array}{c}1.9 \pm 1.9 \\
3.4 \pm 0.6 \\
78.9\end{array}$ & - & $\begin{array}{ll}- \\
-\end{array}$ & $\begin{array}{l}3 \\
1\end{array}$ & $\begin{array}{c}25.0 \pm 41.8 \\
11.1 \pm 19.2 \\
-55.6\end{array}$ \\
\hline Centre right & $\begin{array}{l}\text { Males } \\
\text { Females } \\
\text { diff }(\%) \\
\end{array}$ & $\begin{array}{l}4 \\
1\end{array}$ & $\begin{array}{c}1.1 \pm 1.4 \\
0.5 \pm 0.8 \\
-54.5 \\
\end{array}$ & - & $\begin{array}{l}- \\
-\end{array}$ & $\begin{array}{l}2 \\
1\end{array}$ & $\begin{array}{c}16.7 \pm 40.8 \\
33.3 \pm 57.7 \\
99.4\end{array}$ \\
\hline Centre left & $\begin{array}{l}\text { Males } \\
\text { Females } \\
\text { diff }(\%)\end{array}$ & $\begin{array}{l}2 \\
6\end{array}$ & $\begin{array}{c}0.8 \pm 1.9 \\
2.9 \pm 0.2 \\
262.5 \\
\end{array}$ & - & $\begin{array}{ll}- \\
-\end{array}$ & $\begin{array}{l}1 \\
-\end{array}$ & $\begin{array}{c}8.3 \pm 20.4 \\
- \\
-100.0\end{array}$ \\
\hline Back all (including directive goals) & $\begin{array}{l}\text { Males } \\
\text { Females } \\
\text { diff }(\%)\end{array}$ & $\begin{array}{c}19 \\
5\end{array}$ & $\begin{array}{c}6.4 \pm 5.2 \\
2.3 \pm 2.8 \\
-64.1 \\
\end{array}$ & $\begin{array}{l}2 \\
2\end{array}$ & $\begin{array}{c}11.1 \pm 20.2 \\
41.7 \pm 52.0 \\
275.7\end{array}$ & $\begin{array}{c}10 \\
-\end{array}$ & $\begin{array}{c}40.6 \pm 32.0 \\
- \\
-100.0 \\
\end{array}$ \\
\hline Back right & $\begin{array}{l}\text { Males } \\
\text { Females } \\
\text { diff }(\%)\end{array}$ & $\begin{array}{l}3 \\
1\end{array}$ & $\begin{array}{c}1.0 \pm 1.6 \\
0.5 \pm 0.8 \\
-50.0\end{array}$ & - & $\begin{array}{l}- \\
- \\
-\end{array}$ & $\begin{array}{l}3 \\
-\end{array}$ & $\begin{array}{c}33.3 \pm 51.6 \\
- \\
-100.0\end{array}$ \\
\hline Back left & $\begin{array}{l}\text { Males } \\
\text { Females } \\
\text { diff }(\%) \\
\end{array}$ & $\begin{array}{l}4 \\
-\end{array}$ & $\begin{array}{c}1.4 \pm 2.8 \\
- \\
-100.0 \\
\end{array}$ & $\begin{array}{ll}- \\
-\end{array}$ & $\begin{array}{l}- \\
- \\
-\end{array}$ & $\begin{array}{l}3 \\
-\end{array}$ & $\begin{array}{c}27.8 \pm 44.3 \\
- \\
-100.0\end{array}$ \\
\hline $\begin{array}{l}\text { Pearson's chi-squared } \\
p\end{array}$ & & $\begin{array}{l}8.703 \\
0.275\end{array}$ & & $\begin{array}{l}0.847 \\
0.838\end{array}$ & & $\begin{array}{l}8.222 \\
0.313\end{array}$ & \\
\hline
\end{tabular}

abs - absolute frequency, rel - relative frequency, GKs - goalkeepers, diff (\%) - percentage of differences

A relevant technical aspect of beach handball shooting is the 6-m shot, the penalty throw awarded by the referee. Therefore, it is not a technical-tactical choice of the players and, as for the indoor handball [34], only the GK and the shooter are involved. The shooter can benefit from the short distance from the goal and the central shooting position, and the GK has little chance to block the ball. Thus, it is not surprising that players had higher efficiency and GKs lower efficiency when compared with the other types of shot, with females showing higher values than males.

To the best of our knowledge, none of the studies investigating beach handball shots focused on the different shooting areas. In the present study, the most frequent shooting area was the front (areas 3 and 6), for both males and females. Although no gender differences emerged, male players shot more frequently from the back area, while female GKs were more efficient when receiving shots from the back. It is possible that shooting from the back area requires more strength than shooting from the front owing to the distance from the goal, thus favouring male players, who are usually stronger than female ones [9]. The difficulty in shooting from the back could also depend on the velocity of the defensive system often leading to a directive goal. In fact, a slow defensive system gives the offensive team more time in numerical superiority, where the GK has a chance to shoot quickly with a directive goal before 
A. Iannaccone, A. Fusco, D. Conte, C. Cortis, Notational analysis of beach handball

Table 6. Absolute $(n)$ and relative (means \pm standard deviations) values, and percentages of differences between genders for frequencies of shots, GKs' saves, and goals with GKs and players efficiencies observed in relation to the goal area in males and females

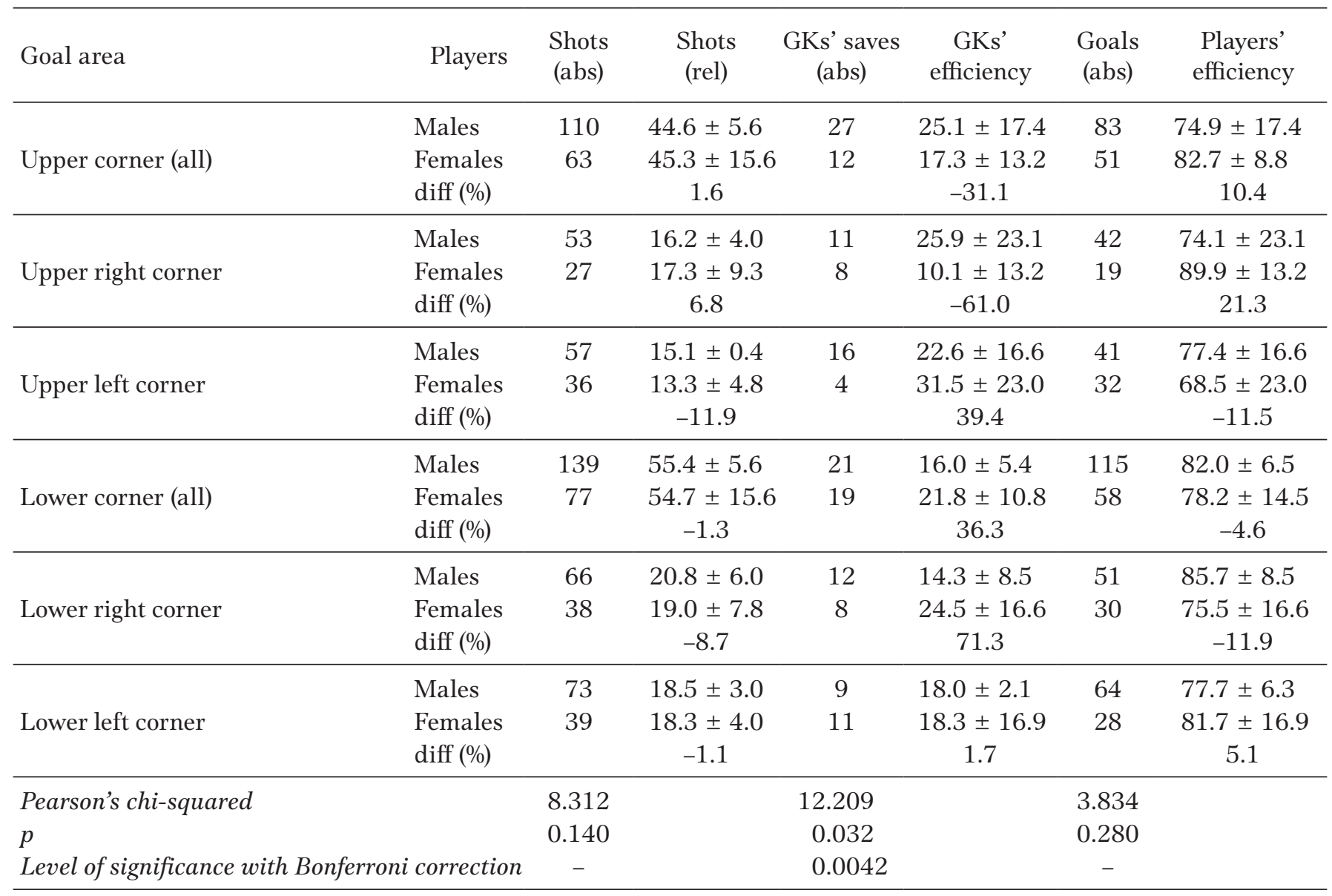

abs - absolute frequency, rel - relative frequency, GKs - goalkeepers, diff (\%) - percentage of differences

the teams reach the numerical balance. Conversely, if the ball is slower, the GK of the team in numerical inferiority could have more time to re-enter the goal area, having more opportunity to save the goal. Furthermore, for team handball, and probably true also for beach handball, it has been demonstrated [35] that high throwing velocity and efficiency are inversely related, suggesting that there is a need of identifying the right combination between efficiency and velocity.

With respect to the goal area, most of the shots in the present study reached the lower corners, coherent with findings reported in a previous study [4]. Male players showed higher efficiency values when shooting to the upper right corner, while female players presented highest efficiency values when shooting to the lower right corner. Male GKs were most efficient when defending the upper right corner of the goal and female GKs when defending the upper left corner of the goal. One of the main factors influencing the success of a shot could be the anticipatory strategy of GK, as for team handball [36], in which it has been demonstrated that GKs are able to identify the clues suggesting the goal side in advance, although it is more difficult to predict the height of the shot.

When analysing shooting efficiencies, several variables, including anthropometric characteristics, should be taken into consideration. In fact, female GKs are typically lower than male ones; thus, they might have more difficulties in reaching the highest corner of the goal to save the ball [4]. Moreover, the shooting efficiency could also be influenced by the defensive systems, especially used at the national level. In particular, the defensive systems try to reduce the shooting efficiency by stealing the ball from the opponents or by inducing the offensive teams to make mistakes while attacking [37].

Although meaningful data have been shown from the present study, some limitations should be considered when interpreting the findings. Firstly, the sample included senior club players and the results might 
not be generalized to different levels of competitions and ages. Secondly, in the present study, it was not possible to collect the players' anthropometric data. As anthropometrics could affect the throwing performance $[9,15,18]$, further research should also investigate the possible impact of players' anthropometric characteristics on their shooting efficiencies. Moreover, only semifinal and final phases of the tournament were recorded, giving the possibility to analyse a limited number of shots. Therefore, future studies should examine whether qualification and eliminatory phases might influence players' and GKs' efficiencies. Finally, as technical and tactical indicators are regularly affected by the margin of victory (i.e., score difference between teams) [38], further research should control for the score between opposite teams.

\section{Conclusions}

The findings from the present study could provide valuable information for coaches and practitioners, helping them to develop training strategies to make the dynamic system of a beach handball match more unpredictable for the opponent. From the present study, no statistically significant differences between genders emerged for the shots on goal made during the semifinal and final phases of the Calise Cup tournament. However, it is important to examine not only the outcome of the shots but also the other related aspects, such as the shooting area and the goal area. For this, notational analysis proved to be a valuable tool for better coaching through the interpretation of technical and tactical aspects of shots in beach handball.

Some observations can be made for planning training strategies. In particular, female players tended to prefer spin shots over the other types of shot but the highest efficiency was achieved for inflight shots, meaning that the technique of spin shot should be improved. Also, coaches should pay their attention to the specialist player. In fact, this player has the chance to score 2 points without doing a spectacular action. In the present study, the second most frequent type of shot was the specialist only in males, but it was not the most efficient when compared with the other types. For GKs, training should be focused on improving the anticipatory strategy during the situation of a 6-m shot in order to increase the possibility to save the ball. Moreover, the ability to use the directive goal should be specifically trained as the offensive team has the advantage of the numerical superiority.

The majority of shots were performed from the front shooting area, where players showed highest values of efficiency when compared with the other shooting areas. GKs also presented highest values of efficiency for shots originating in the front shooting area. However, both male and female GKs were not able to save the ball when the shot came from the centre, which suggests that specific training strategies should be adopted to improve this aspect.

Most of the shots ended in the lower corners of the goal and players were most efficient when shooting to that area, while GKs were most efficient when defending the upper corners of the goal. Since shots usually reach that area, coaches should focus more on the ability to defend the lower corners of the goal when training GKs.

Further research should be conducted to investigate the other contextual factors related to shooting in beach handball, such as the match outcome, the scoring differences, or the ball possession.

\section{Acknowledgments}

The authors would like to express their gratitude to the technical staff of the Calise Cup tournament for their support in the achievement of the match videorecordings.

\section{Disclosure statement}

No author has any financial interest or received any financial benefit from this research.

\section{Conflict of interest}

The authors state no conflict of interest.

\section{References}

1. International Handball Federation. IX. Rules of the game. b) Beach handball. International Handball Federation; 2014.

2. Lara Cobos D, Sánchez Sáez JA, Morillo Baro JP, Sánchez Malia JM. Beach handball game cycle [in Spanish]. Rev Int Deportes Colect. 2018;34:89-100.

3. Gruić I, Vuleta D, Bazzeo M, Ohnjec K. Situational efficiency of teams in female part of tournament in the World Beach Handball Championship in Cadiz. In: Milanović D, Sporiš G (eds.), $6^{\text {th }}$ International Scientific Conference on Kinesiology, 2011, Opatija, Croatia. Zagreb: Kineziološki fakultet; 2011; 524-529.

4. Skandalis V, Hatzimanouil D, Papanikolaou F, Kanioglou A, Yiannakos A. Effectiveness analysis in shooting in European Beach Handball Tournament (EBT) 2016. Phys Train. 2017.

5. Hughes M, Franks IM. Essentials of performance analysis in sport, $2^{\text {nd }}$ ed. New York: Routledge; 2015.

6. Michalsik LB, Madsen K, Aagaard P. Match performance and physiological capacity of female elite team 
A. Iannaccone, A. Fusco, D. Conte, C. Cortis, Notational analysis of beach handball

handball players. Int J Sports Med. 2014;35(7):595607; doi: 10.1055/s-0033-1358713.

7. Wagner H, Finkenzeller T, Würth S, von Duvillard SP. Individual and team performance in team-handball: a review. J Sports Sci Med. 2014;13(4):808-816.

8. Wagner H, Fuchs PX, von Duvillard SP. Specific physiological and biomechanical performance in elite, sub-elite and in non-elite male team handball players. J Sports Med Phys Fitness. 2018;58(1-2):73-81; doi: 10.23736/S0022-4707.16.06758-X.

9. Wagner H, Fuchs P, Fusco A, Fuchs P, Bell JW, von Duvillard SP. Physical performance in elite male and female team-handball players. Int J Sports Physiol Perform. 2019;14(1):60-67; doi: 10.1123/ijspp.2018-0014.

10. Pueo B, Jimenez-Olmedo JM, Penichet-Tomas A, Ortega Becerra M, Espina Agullo JJ. Analysis of time-motion and heart rate in elite male and female beach handball. J Sports Sci Med. 2017;16(4):450-458.

11. Lara Cobos D. Analysis of heart rate in female beach handball players. Apunts Sports Med. 2011;46(171): 131-136; doi: 10.1016/j.apunts.2011.02.001.

12. Valtner TT, Lara Cobos D, de Almeida AG. Heart rate responses in beach handball match. In: Anais do $5^{\circ}$ Congresso Internacional de Jogos Desportivos. Belo Horizonte: 2015; 793-798; doi: 10.13140/RG.2.2.20238. 36165 .

13. Gutiérrez-Vargas R, Gutiérrez-Vargas JC, UgaldeRamírez JA, Rojas-Valverde D. Kinematics and thermal sex-related responses during an official beach handball game in Costa Rica: a pilot study. Arch Med Deporte. 2019;36(1):13-18.

14. Zapardiel JC, Asín-Izquierdo I. Conditional analysis of elite beach handball according to specific playing position through assessment with GPS. Int J Perform AnalSport. 2020;20(1):118-132; doi: 10.1080/24748668. 2020.1718458 .

15. Jimenez-Olmedo JM, Penichet-Tomas A, Ortega Becerra M, Pueo B, Espina-Agullo JJ. Relationships between anthropometric parameters and overarm throw in elite beach handball. Hum Mov. 2019;20(2):16-24; doi: $10.5114 / \mathrm{hm} .2019 .79394$.

16. Gkagkanas K, Hatzimanouil D, Skandalis V. Gender differentiation in tactical options in defense and attack on beach handball. Exerc Qual Life. 2018;10(2):2330; doi: 10.31382/eqol.181203.

17. Navarro A, Morillo JP, Reigal RE, Hernández-Mendo A. Polar coordinate analysis in the study of positional attacks in beach handball. Int J Perform Anal Sport. 2018; 18(1):151-167; doi: 10.1080/24748668.2018.1460052.

18. Michalsik LB, Aagaard P. Physical demands in elite team handball: comparisons between male and female players. J Sports Med Phys Fitness. 2015;55(9):878891.

19. Lupo C, Capranica L, Cugliari G, Gomez MA, Tessitore A. Tactical swimming activity and heart rate aspects of youth water polo game. J Sports Med Phys Fitness. 2016;56(9):997-1006.
20. Lupo C, Tessitore A, Minganti C, Capranica L. Notational analysis of elite and sub-elite water polo matches. J Strength Cond Res. 2010;24(1):223-229; doi: 10.1519/JSC.0b013e3181c27d36.

21. Hatzimanouil D. Throwing effectiveness per throwing area and playing position among high level handball players. J Phys Educ Sport Manag. 2019;6(1):13-20; doi: 10.15640/jpesm.v6n1a2.

22. Prieto J, Gómez M-Á, Sampaio J. From a static to a dynamic perspective in handball match analysis: a systematic review. Open Sports Sci J. 2015;8:25-34; doi: 10.2174/1875399x01508010025.

23. Wright C, Atkins S, Jones B. An analysis of elite coaches' engagement with performance analysis services (match, notational analysis and technique analysis). Int J Perform Anal Sport. 2012;12(2):436-451; doi: 10.1080/24748668.2012.11868609.

24. Hughes MD, Bartlett RM. The use of performance indicators in performance analysis. J Sports Sci. 2002;20(10): 739-754; doi: 10.1080/026404102320675602.

25. Bělka J, Hůlka K, Šafář M, Weisser R, Chadimova J. Beach handball and beach volleyball as means leading to increasing physical activity of recreational sportspeople - pilot study. J Sport Sci. 2015;3:165-170; doi: 10.17265/2332-7839/2015.04.002.

26. Saavedra JM, Pic M, Jimenez F, Lozano D, Kristjánsdóttir H. Relationship between game-related statistics in elite men's beach handball and the final result: a classification tree approach. Int J Perform Anal Sport. 2019;19(4):584-594; doi: 10.1080/24748668.2019. 1642040 .

27. Morillo-Baro JP, Reigal RE, Hernández-Mendo A. Analysis of positional attack in beach handball male and female with polar coordinates [in Spanish]. Rev Int Cienc Deporte. 2015;11(41):226-244; doi: 10.5232/ ricyde2015.04103.

28. Bon M, Pori P. Various aspects of the scientific development of beach handball over three decades - from "Keep it simple" to the Olympic Games. Sport Mont. 2020;18(2):103-106; doi: 10.26773/smj.200618.

29. Robinson G, O’Donoghue P. A weighted kappa statistic for reliability testing in performance analysis of sport. Int J Perform Anal Sport. 2007;7(1):12-19; doi: 10.1080/24748668.2007.11868383.

30. Landis JR, Koch GG. The measurement of observer agreement for categorical data. Biometrics. 1977;33(1): 159-174; doi: 10.2307/2529310.

31. O’Donoghue P, Holmes L. Data analysis in sport. London: Routledge; 2014.

32. Lara Cobos D, Sánchez Sáez JA. Qualitative analysis of female beach handball: 2013-2017 [in Spanish]. Rev Int Deportes Colect. 2018;35:83-95.

33. Zapardiel JC. Beach handball European championships analysis Zagreb 2017. EHF Web Period. 2018;126.

34. Hatzimanouil D, Giatsis G, Kepesidou M, Kanioglou A, Loizos N. Shot effectiveness by playing position with 
regard to goalkeeper's efficiency in team handball. J Phys Educ Sport. 2017;17(2):656-662; doi: 10.7752/ jpes.2017.02098.

35. Vila H, Zapardiel JC, Ferragut C. The relationship between effectiveness and throwing velocity in a handball match. Int J Perform Anal Sport. 2020;20(2):180188; doi: 10.1080/24748668.2020.1726159.

36. Gutierrez-Davila M, Rojas FJ, Ortega M, Campos J, Parraga J. Anticipatory strategies of team-handball goalkeepers. J Sports Sci. 2011;29(12):1321-1328; doi: 10.1080/02640414.2011.591421.

37. Gkagkanas K, Hatzimanouil D, Skandalis V, Dimitriou S, Papadopoulou SD. Defense tactics in high-level teams in beach handball. J Phys Educ Sport. 2018;18(2):914-920; doi: 10.7752/jpes.2018.02135.

38. Lupo C, Tessitore A. How important is the final outcome to interpret match analysis data: the influence of scoring a goal, and difference between close and balance games in elite soccer: comment on Lago-Penas and Gomez-Lopez (2014). Percept Mot Skills. 2016;122(1): 280-285; doi: 10.1177/0031512515626629. 